\title{
Analisis Perancangan Frame Gokart dari Pengaruh Pembebanan dengan Menggunakan CAD Solidworks 2016
}

\author{
Angga Restu Pahlawan ${ }^{1)^{\star}}$, Rizal Hanifi ${ }^{2)}$, Aa Santosa ${ }^{3)}$ \\ ${ }^{1)}$ Program Studi Teknik Mesin Universitas Singaperbangsa Karawang \\ Kabupaten Karawang, Jawa Barat 41361 \\ Email: anggapahlawan12@gmail.com \\ 2,3) Jurusan Teknik Mesin, Universitas Singaperbangsa Karawang \\ Kabupaten Karawang, Jawa Barat 41361 \\ Email: rizal.hanifi@ft.unsika.ac.id, aa.santosa@ft.unsika.ac.id
}

doi: https://doi.org/10.24843/METTEK.2021.v07.i01.p01

\begin{abstract}
Abstrak
Frame adalah salah satu komponen yang sangat penting dalam sebuah kendaraan, yang berfungsi sebagai penopang penumpang, mesin, suspensi, sistem kelistrikan dan lain-lain. Melihat fungsi dari frame sangat penting, maka dalam merancang sebuah frame harus diperhitungkan dengan baik. Banyak sekali jenis pengujian yang sering dipakai dalam perancangan sebuah struktur frame, salah satunya adalah digunakannya metode komputasi dengan menggunakan metode Finite Element Analysis (FEA). Tujuan dari penelitian ini adalah untuk mengetahui distribusi tegangan, regangan, displacement, dan safety factor dari hasil pembebanan statis pada frame gokar. Struktur frame didesain dan dianalisis menggunakan software Solidworks 2016. Material yang digunakan frame adalah baja AISI 1045 hollow tube $27 \times 3,2 \mathrm{~mm}$, dengan menggunakan pembebanan pengendara sebesar $50 \mathrm{~kg}$ dan $70 \mathrm{~kg}$. Hasil dari perhitungan manual didapatkan tegangan maksimum sebesar 4,735 $\times 10^{7} \mathrm{~N} / \mathrm{m}^{2}$, sedangkan dari simulasi didapatkan sebesar 4,516 $\times 10^{7} \mathrm{~N} / \mathrm{m}^{2}$. Regangan maksimum didapatkan dari perhitungan manual sebesar $2,310 \times$ $10^{-4}$. Displacement maksimum didapatkan dari perhitungan manual sebesar 1,864 $\times 10^{8}$ $\mathrm{mm}$, sedangkan dari simulasi didapatkan sebesar $1,624 \times 10^{8} \mathrm{~mm}$. Safety factor minimum didapatkan dari perhitungan manual sebesar 11,193, dan perhitungan simulasi didapatkan sebesar 11,736 .
\end{abstract}

Kata kunci: Frame, FEA, baja AISI 1045, Solidworks 2016.

\begin{abstract}
The frame is one of the most important components in a vehicle, which functions as a support for passengers, engines, suspensions, electrical systems and others. Seeing the function of the frame is very important, so designing a frame must be taken into account well. There are many types of tests that are often used in the design of a frame structure, one of which is the use of computational methods using the Finite Element Analysis (FEA) method. The purpose of this study was to determine the distribution of stress, strain, displacement, and safety factor from the results of static loading on the kart frame. The frame structure was designed and analyzed using Solidworks 2016 software. The material used in the frame is steel AISI 1045 hollow tube $27 \times 3,2 \mathrm{~mm}$, using a rider load of $50 \mathrm{~kg}$ and $70 \mathrm{~kg}$. The result of manual calculation shows that the maximum stress is $4,735 \times 10^{7} \mathrm{~N} / \mathrm{m}^{2}$, while the simulation results are $4,516 \times 10^{7} \mathrm{~N} / \mathrm{m}^{2}$. The maximum strain is obtained from manual calculation of $2,310 \times 10^{-4}$. The maximum displacement is obtained from manual calculations of $1,864 \times 10^{8} \mathrm{~mm}$, while the simulation results are $1,624 \times 10^{8} \mathrm{~mm}$. The minimum safety factor obtained from manual calculation is 11,193, and the simulation calculation is 11,736.
\end{abstract}

Keywords: Frame, FEA, AISI 1045 steel, Solidworks 2016.

Penulis korespondensi,

Email: anggapahlawan12@gmail.com 


\section{PENDAHULUAN}

Pertumbuhan kendaraan bermotor khususnya di Indonesia setiap tahunnya terus mengalami peningkatan, baik itu jenis kendaraan roda empat maupun kendaraan roda dua. Berdasarkan data Badan Pusat Statistik jumlah kendaraan di Indonesia pada tahun 2018 untuk kendaraan mobil penumpang sebanyak 16. 440.987 unit, mobil bis sebanyak 2.538.182 unit, mobil barang sebanyak 7.778.544 unit, dan jumlah sepeda motor 120.101.047 unit. Dari hasil data yang didapat menunjukkan bahwa jumlah total kendaraan bermotor secara keseluruhan pada tahun 2018 mencapai 146.858 .759 unit [1].

Industri otomotif adalah merupakan salah satu pasar industri yang memiliki kemajuan yang sangat pesat. Salah satu bentuk perkembangan dan pembaharuan teknologi pada industri otomotif ini antara lain yaitu di bidang rangka (frame) dari sebuah kendaraan. Dan bahkan rangka sekarang banyak diaplikasikan dan dikembangkan pada kendaraan kategori prototype, seperti kendaraan gokar. Frame merupakan salah satu komponen terpenting dalam sebuah kendaraan, yang berfungsi sebagai penopang mesin, sistem suspensi dan sistem kelistrikan, sehingga menjadi satu kesatuan yang membuat sebuah kendaraan dapat berjalan. Oleh sebab itu, rangka harus memiliki sifat yang kuat, ringan, dan tahan terhadap getaran atau goncangan yang diterima dari beban penumpang, mesin dan kondisi jalan [2]. Pembebanan pada rangka akan mempengaruhi terjadinya defleksi pada konstruksi rangka tersebut sehingga rawan terjadinya retakan dan bahkan patahan. Melihat fungsi dari rangka sangat penting pada sebuah kendaraan, maka dalam merancang sebuah rangka harus diperhitungkan dengan baik dan benar untuk meminimalisir terjadinya kegagalan pada rangka. Maka dari itu faktor keamanan dari perancangan rangka menjadi perhatian khusus. Berbagai metode pengujian sudah banyak dilakukan untuk memperoleh hasil perancangan frame agar dapat memenuhi standar keamanan.

Adapun jenis pengujian yang sering dipakai dalam perancangan struktur adalah digunakannya metode komputasi dengan menggunakan metode elemen hingga atau FEA (Finite Element Analysis). Metode finite element analysis adalah sebuah metode penyelesaian numerik yang menggunakan pendekatan dengan membagi-bagi (diskritasi) benda yang akan dianalisa menjadi bentuk elemen-elemen yang berhingga dan saling berkaitan. FEA sendiri banyak digunakan dalam permasalahan di dunia engineering, misalnya menganalisis kekuatan struktur, korosi, perpindahan panas, elektromagnetis, dan aliran fluida [3].

Berdasarkan latar belakang di atas peneliti bertujuan merancang sebuah frame gokar dan melakukan analisis dengan menggunakan software Solidworks 2016, untuk mengetahui kekuatan dari struktur frame terhadap proses pembebanan yang dilakukan.

\section{METODE}

\subsection{Persamaan}

Untuk mengetahui kekuatan dari struktur frame, maka dilakukan suatu perhitungan menggunakan persamaan-persamaan sebagai berikut:

a) Konsep tegangan

Secara umum tegangan pada elemen dibagi menjadi 2 bagian, yaitu tegangan normal dan tegangan geser. Seperti yang diketahui bahwa tegangan timbul akibat adanya beban yang bekerja pada suatu elemen batang. Ada 2 jenis beban yang bisa menyebabkan tegangan normal, yang pertama adalah gaya aksial baik berupa gaya tarik ataupun gaya tekan, dan kedua adalah momen lentur berupa gaya radial [4]. Tegangan normal maksimum yang di sebabkan oleh momen lentur dari gaya radial yang terjadi pada frame gokar dapat dirumuskan dengan persamaan berikut:

$$
\sigma_{m a k s}=\frac{M_{L} \cdot y}{I}
$$


Dimana:

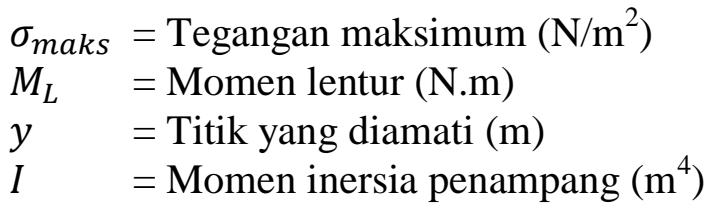

b) Regangan

Regangan pada suatu benda terjadi apabila benda tersebut mengalami perubahan panjang yang diakibatkan oleh gaya radial. Regangan mempunyai ciri yang sama dengan tegangan, dimana regangan diakibatkan dari tekanan dan tarikan. Menurut Ramadhan dan kawan-kawan [5], Untuk mencari regangan dapat dirumuskan persamaan berikut:

$$
\varepsilon=\frac{\sigma_{m a k s}}{E}
$$

Dimana:

$\varepsilon \quad=$ Regangan

$\sigma_{\text {maks }}=$ Tegangan maksimum $\left(\mathrm{N} / \mathrm{m}^{2}\right)$

$E \quad=$ Modulus elastisitas $\left(\mathrm{N} / \mathrm{m}^{2}\right)$

c) Defleksi

Menurut Ferdinand dan kawan-kawan [6], defleksi adalah perubahan bentuk pada balok dalam arah y akibat adanya pembebanan vertikal yang diberikan pada balok atau batang. Deformasi pada balok secara sangat mudah dapat dijelaskan berdasarkan defleksi balok dari posisinya sebelum mengalami pembebanan. Defleksi diukur dari permukaan netral awal ke posisi netral setelah terjadi deformasi. Adapun rumus defleksi yang dipakai yaitu menurut jenis dan tumpuannya sebagai berikut:

$$
\delta=\frac{P \cdot a}{24 \cdot E . I}\left(3 \cdot L^{2}-4 \cdot a^{2}\right)
$$

Dimana:

$\delta .=$ Defleksi $(\mathrm{mm})$

$P=$ Beban yang diberikan $(\mathrm{N})$

$E=$ Modulus elastisitas $\left(\mathrm{N} / \mathrm{m}^{2}\right)$

$I=$ Momen inersia penampang $\left(\mathrm{m}^{4}\right)$

$L=$ Jarak keseluruhan batang $(\mathrm{m})$

$a=$ Jarak pembebanan $(\mathrm{m})$

d) Safety factor

Safety Factor (faktor keamanan) adalah suatu faktor yang digunakan untuk mengevaluasi sebuah perencanaan elemen mesin agar terjamin keamanannya. Menurut Dobrovolsky, V [7], faktor keamanan diberikan kepada suatu desain biasanya berdasarkan jenis pembebanan yaitu pembebanan statis: $1,25-2$, pembebanan dinamis: $2-3$, dan pembebanan kejut: 3 - 5. [8] Adapun rumus yang digunakan untuk mengetahui faktor keamanan dari suatu material dalam perencanaan elemen mesin dirumuskan pada persamaan berikut:

$$
\mathrm{FS}=\frac{S_{y}}{\sigma_{\text {actual }}}
$$


Dimana:

FS $\quad=$ Faktor keamanan

$S_{y} \quad=$ Tegangan luluh material $\left(\mathrm{N} / \mathrm{m}^{2}\right)$

$\sigma_{\text {actual }}=$ Tegangan yang terjadi $\left(\mathrm{N} / \mathrm{m}^{2}\right)$

\subsection{Prosedur Penelitian}

Adapun prosedur dari penelitian:

1. Menyiapkan alat.

2. Menyiapkan data perencanaan.

3. Menyiapkan standar perancangan.

4. Menyiapkan software Solidworks premium 2016.

5. Menentukan geometri atau pemodelan.

6. Melakukan simulasi dengan aplikasi software Solidworks premium 2016.

\subsection{Alat dan Bahan Penelitian}

Alat dan bahan yang digunakan dalam penelitian adalah sebagai berikut:

1. Laptop Asus A407M.

2. Software Solidworks Premium 2016 yang digunakan untuk mendesain rangka gokar dan untuk melakukan simulasi.

3. Buku referensi yang berkaitan dengan penelitian yang sedang dilakukan untuk mendapatkan landasan teori yang sesuai dengan penelitian.

4. Jurnal berisi hasil-hasil penelitian terdahulu yang berkaitan dengan penelitian yang sedang dikerjakan.

\subsection{Rancangan Penelitian}

Metode penelitian yang digunakan adalah metode eksperimen, yang meliputi perancangan dan analisis rangka gokar secara teoritis dengan proses metode elemen hingga pada simulasi. Bahan yang digunakan frame adalah baja AISI 1045 dengan profil hollow tube $27 \times 3,2 \mathrm{~mm}$, adapun sifat mekanik dari baja AISI 1045 yang digunakan penelitian diambil dari software Solidworks 2016, yang mempunyai nilai elastic modulus sebesar 2,050 $\times 10^{11}$ $\mathrm{N} / \mathrm{m}^{2}$, tensile strength sebesar $6,250 \times 10^{8} \mathrm{~N} / \mathrm{m}^{2}$, dan yield strength sebesar $5,300 \times 10^{8}$ $\mathrm{N} / \mathrm{m}^{2}$. Adapun standar yang digunakan pada perancangan desain frame gokar mengacu pada regulasi kontes mobil hemat energi 2017. Dimensi rangka gokar yang dibuat bisa dilihat pada gambar 1 .

Skema penelitian, dimana dilakukan perhitungan manual dan simulasi menggunakan software Solidworks 2016 sebanyak dua kali untuk proses pembebanan pada frame gokar. Adapun pembebanan dalam kondisi statis yang diberikan pada frame yaitu beban dari pengendara, kursi gokar dan beban dari mesin gokar, yang masing-masing memiliki beban yang berbeda. Variasi beban pengendara yang digunakan pada penelitian yaitu $50 \mathrm{~kg}$ dan 70 $\mathrm{kg}$, massa dari kursi gokar sebesar $0,73 \mathrm{~kg}$ dan massa dari mesin gokar yaitu $17 \mathrm{~kg}$. Dengan mengasumsikan percepatan gravitasi sebesar $9,8 \mathrm{~m} / \mathrm{s}^{2}$. Dimana untuk mencari gaya dari beban digunakan persamaan sebagai berikut.

$$
\mathrm{W}=\mathrm{m} \cdot \mathrm{g}
$$

Setelah hasil dari perhitungan manual dan hasil dari software didapatkan, kemudian datadata yang didapat dikumpulkan pada tabel, untuk membandingkan hasil dari proses perhitungan manual dan hasil dari software. 


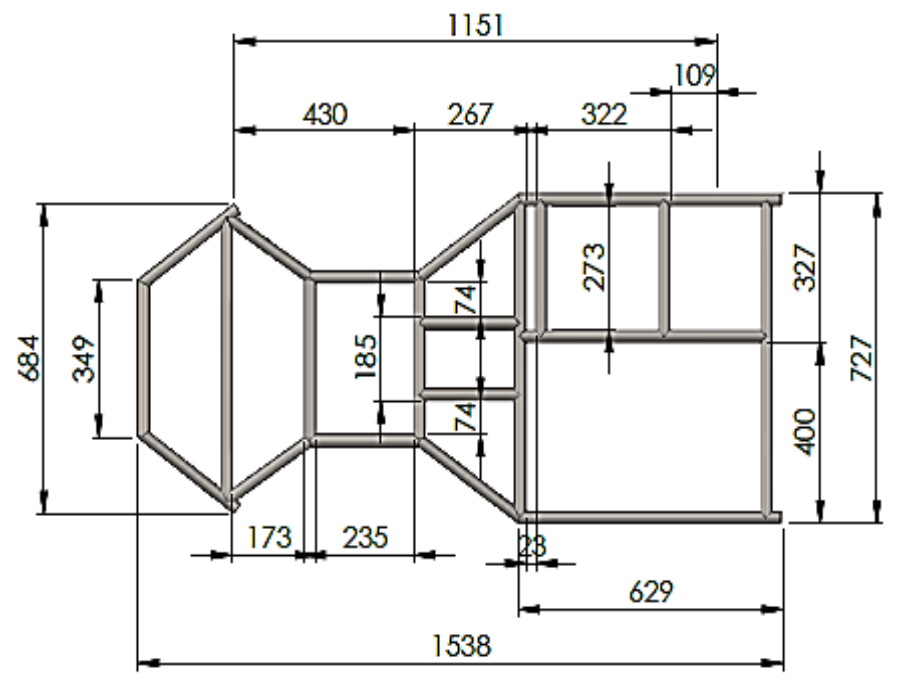

Gambar 1. Dimensi frame gokar

\subsection{Diagram Alir Penelitian}

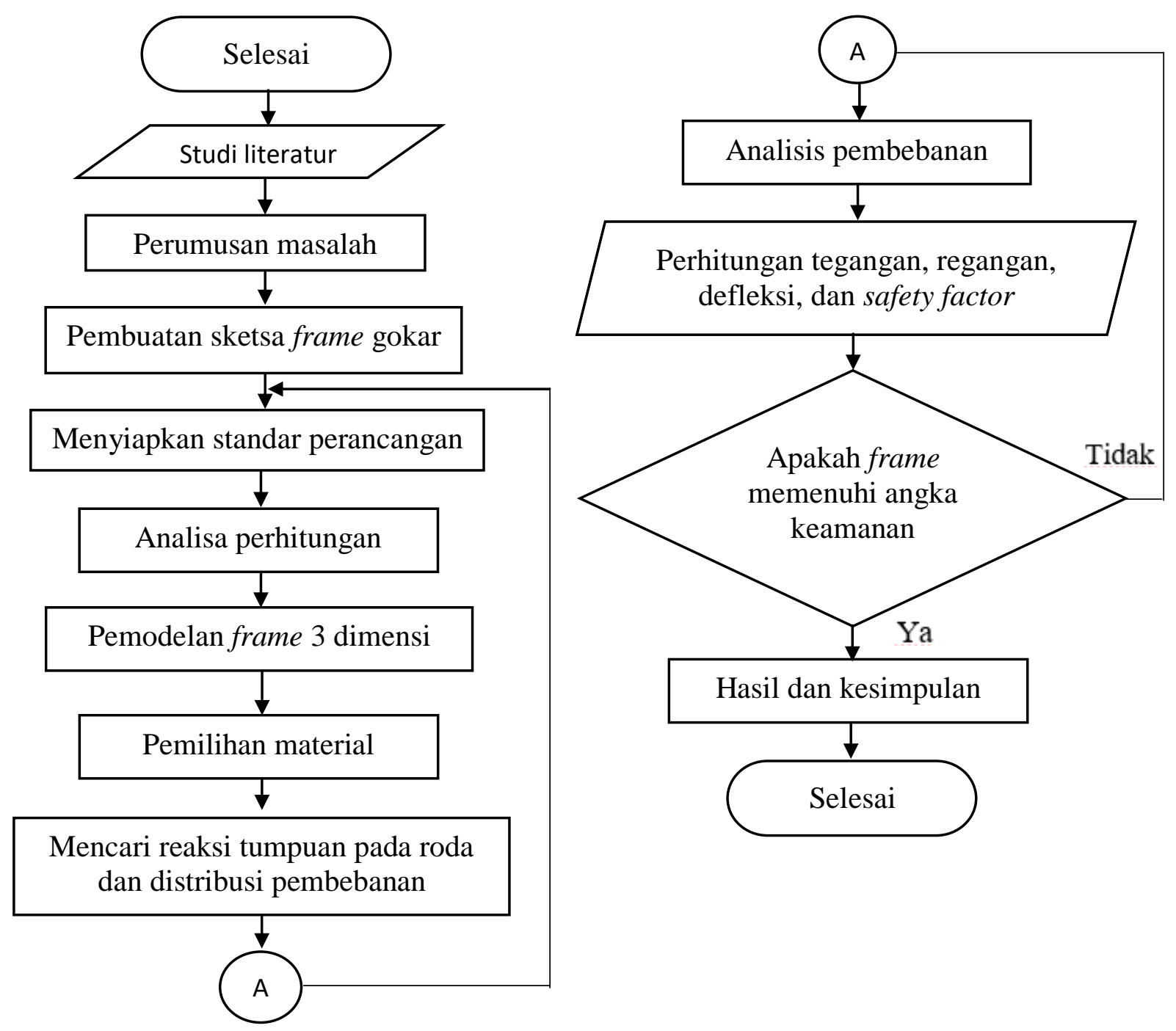

Gambar 2. Diagram alir penelitian 


\section{HASIL DAN PEMBAHASAN}

\subsection{Hasil Simulasi Pada Software Solidworks 2016}

Adapun hasil dari simulasi pada software untuk pembebanan pengendara $50 \mathrm{~kg}$.

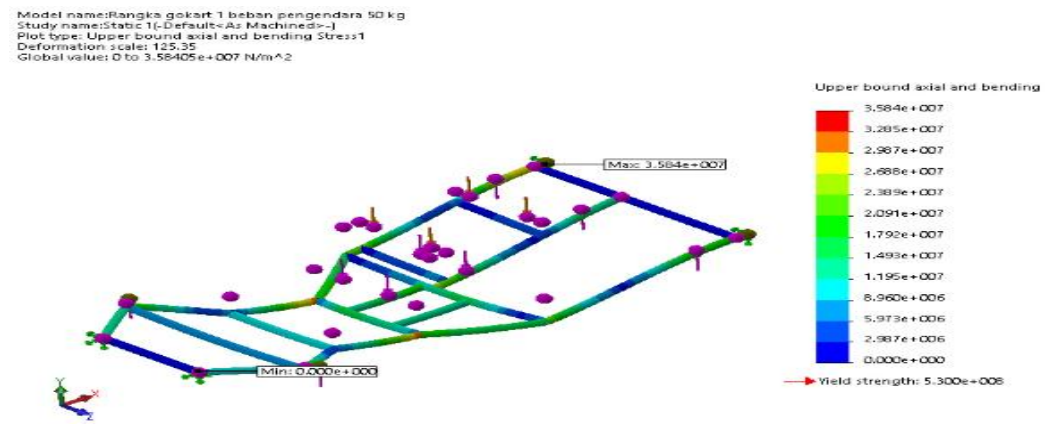

Hasil A

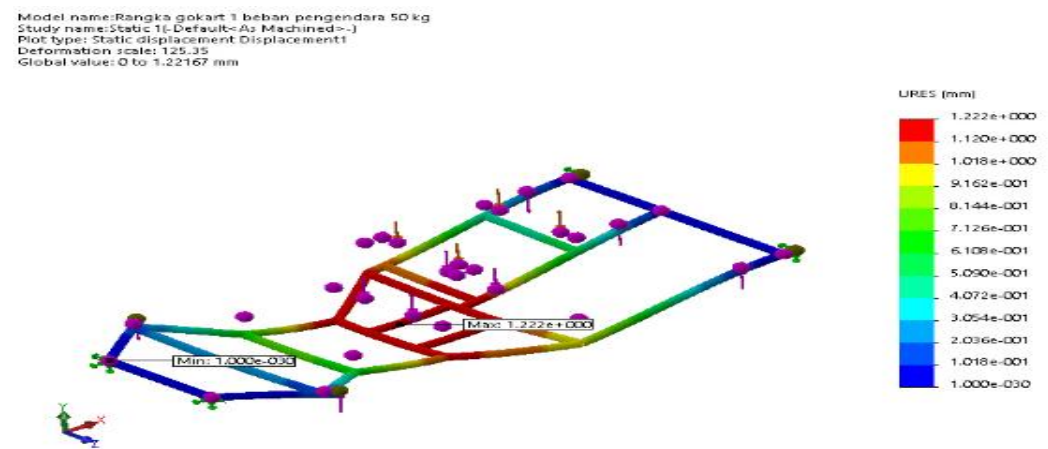

Hasil B

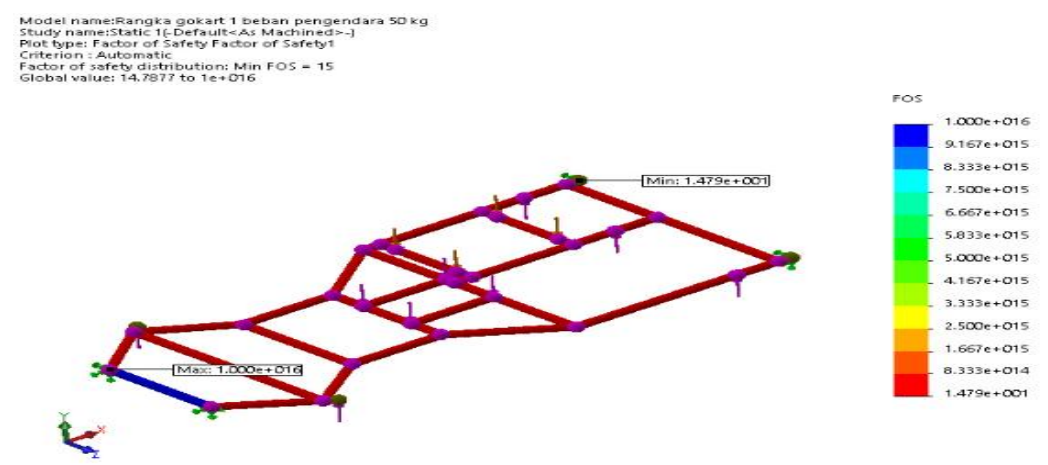

Hasil C

Gambar 3. Hasil simulasi software $\mathrm{A}=$ tegangan maksimum, $\mathrm{B}=$ defleksi, $\mathrm{C}=$ safety factor

Adapun hasil dari simulasi pada software untuk pembebanan pengendara $70 \mathrm{~kg}$
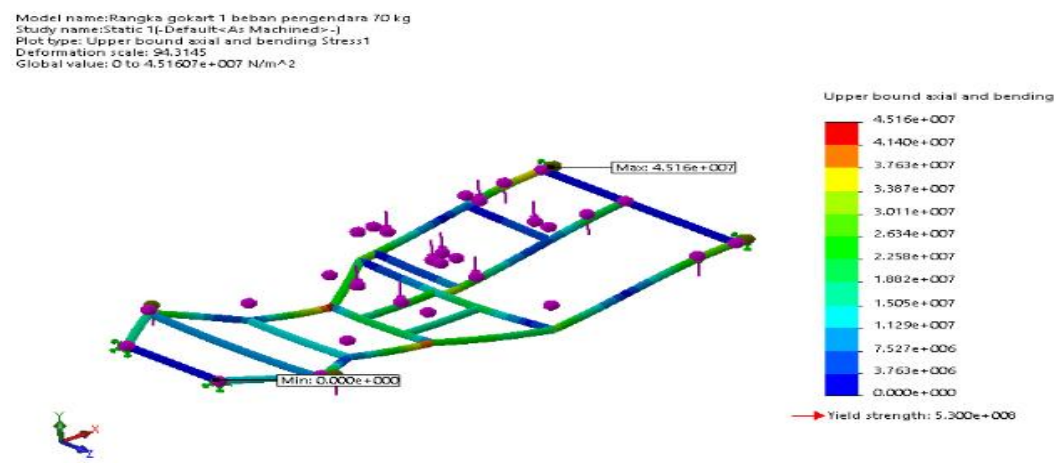

Hasil A 


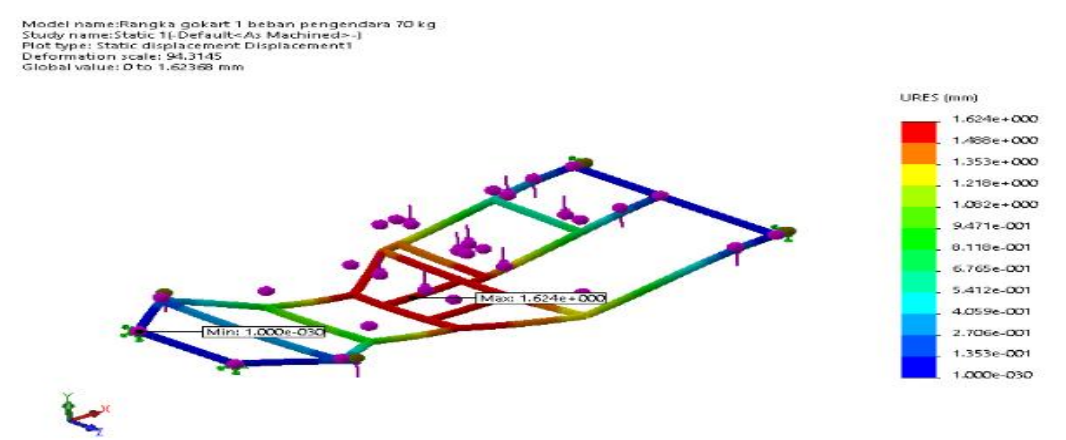

Hasil B

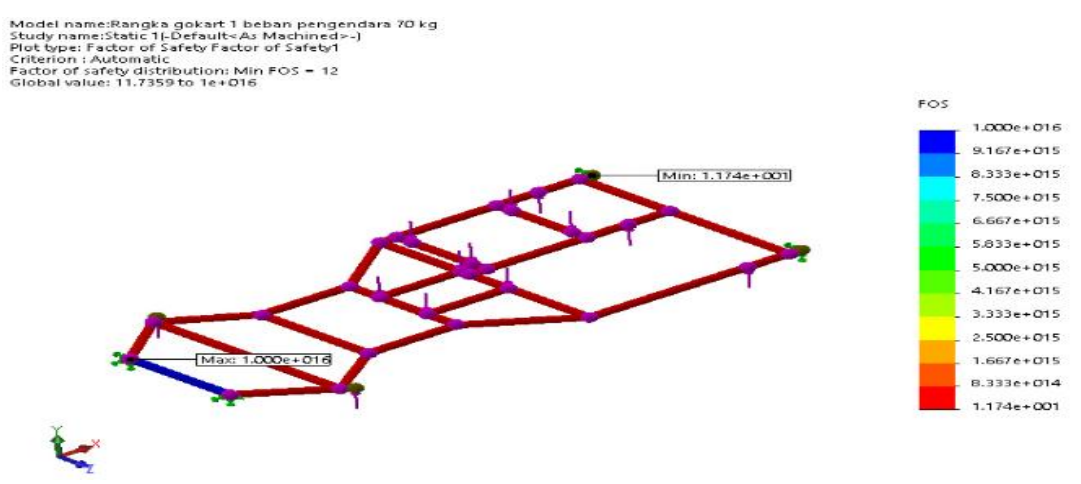

Hasil C

Gambar 4. Hasil simulasi software $\mathrm{A}=$ tegangan maksimum, $\mathrm{B}=$ defleksi, $\mathrm{C}=$ safety factor

\subsection{Data Hasil Perhitungan dan Simulasi}

Besarnya tegangan, regangan, defleksi dan faktor keamanan pada frame dengan pembebanan pengendara $50 \mathrm{~kg}$ dan $70 \mathrm{~kg}$, massa kursi gokar $0,73 \mathrm{~kg}$, dan massa dari mesin gokar sebesar $17 \mathrm{~kg}$, dengan mengasumsikan percepatan gravitasi sebesar $9,8 \mathrm{~m} / \mathrm{s}^{2}$. Berdasarkan hasil perhitungan dan simulasi dapat dilihat pada tabel berikut:

Tabel 1. Hasil perhitungan dan simulasi pada frame dengan beban pengendara $50 \mathrm{~kg}$

\begin{tabular}{cccc}
\hline No & Jenis & Hasil Perhitungan & Hasil simulasi Solidworks \\
\hline 1. & Stress max & $3,597 \times 10^{7} \mathrm{~N} / \mathrm{m}^{2}$ & $3,584 \times 10^{7} \mathrm{~N} / \mathrm{m}^{2}$ \\
2. & Strain max & $1,754 \times 10^{-4}$ & - \\
3. & Displacement max & $1,337 \times 10^{8} \mathrm{~mm}$ & $1,222 \times 10^{8} \mathrm{~mm}$ \\
4. & Safety Factor min & 14,734 & 14,788 \\
\hline
\end{tabular}

Pengaruh pembebanan terhadap rangka dengan beban pengendara sebesar $50 \mathrm{~kg}$ didapatkan tegangan maksimum dari perhitungan manual sebesar $3,597 \times 10^{7} \mathrm{~N} / \mathrm{m}^{2}$, sedangkan tegangan dari simulasi didapatkan sebesar $3,584 \times 10^{7} \mathrm{~N} / \mathrm{m}^{2}$. Hasil regangan maksimum pada perhitungan manual didapatkan sebesar $1,754 \times 10^{-4}$. Dan displacement maksimum dari perhitungan manual didapatkan sebesar $1,337 \times 10^{8} \mathrm{~mm}$, sedangkan displacement dari simulasi didapatkan sebesar $1,222 \times 10^{8} \mathrm{~mm}$. Safety factor minimum didapatkan dari perhitungan manual sebesar 14,734, sedangkan safety factor dari simulasi didapatkan sebesar 14,788. 
Tabel 2. Hasil perhitungan dan simulasi pada frame dengan beban pengendara $70 \mathrm{~kg}$

\begin{tabular}{cccc}
\hline No & Jenis & Hasil Perhitungan & Hasil simulasi Solidworks \\
\hline 1. & Stress max & $4,735 \times 10^{7} \mathrm{~N} / \mathrm{m}^{2}$ & $4,516 \times 10^{7} \mathrm{~N} / \mathrm{m}^{2}$ \\
2. & Strain max & $2,310 \times 10^{-4}$ & - \\
3. & Displacement max & $1,864 \times 10^{8} \mathrm{~mm}$ & $1,624 \times 10^{8} \mathrm{~mm}$ \\
4. & Safety Factor min & 11,193 & 11,736 \\
\hline
\end{tabular}

Pengaruh pembebanan terhadap rangka dengan beban pengendara sebesar $70 \mathrm{~kg}$ didapatkan tegangan maksimum dari perhitungan manual sebesar 4,735 $\times 10^{7} \mathrm{~N} / \mathrm{m}^{2}$, sedangkan tegangan dari simulasi didapatkan sebesar 4,516 $\times 10^{7} \mathrm{~N} / \mathrm{m}^{2}$. Hasil regangan maksimum pada perhitungan manual didapatkan sebesar $2,310 \times 10^{-4}$. Dan displacement maksimum dari perhitungan manual didapatkan sebesar $1,864 \times 10^{8} \mathrm{~mm}$, sedangkan displacement dari simulasi didapatkan sebesar $1,624 \times 10^{8} \mathrm{~mm}$. Safety factor minimum didapatkan dari perhitungan manual sebesar 11,193, sedangkan safety factor dari simulasi didapatkan sebesar 11,736 .

Adapun dari hasil perhitungan yang dilakukan sebelumnya didapatkan tegangan izin material baja AISI 1045 terhadap pembebanan statis sebesar 2,650 × 10 $\mathrm{N} / \mathrm{m}^{2}$.

\section{SIMPULAN}

Dari hasil penelitian didapatkan tegangan, regangan, dan defleksi terbesar yaitu diakibatan dari pembebanan pengendara sebesar $70 \mathrm{~kg}$. Perancangan frame gokar telah memenuhi kriteria aman dari hasil perhitungan manual maupun hasil dari simulasi, dengan menggunakan pembebanan maksimum yang diberikan dari beban pengendara $70 \mathrm{~kg}$, kursi gokar $0,73 \mathrm{~kg}$, dan beban mesin gokar $17 \mathrm{~kg}$. Dikarenakan hasil dari tegangan maksimum yang didapat pada frame sebesar $4,735 \times 10^{7} \mathrm{~N} / \mathrm{m}^{2}$, masih dibawah tegangan izin dari material yaitu sebesar $2,650 \times 10^{8} \mathrm{~N} / \mathrm{m}^{2}$, maka frame dikatakan aman dan layak digunakan. Penggunaan software dalam sebuah penelitian sangat membantu dan efektif terhadap efisiensi waktu yang dibutuhkan. Karena hasil perbandingan perhitungan manual yang dilakukan peneliti dan hasil dari simulasi software pun tidak jauh berbeda.

\section{DAFTAR PUSTAKA}

[1] B. P. Statistik, "Perkembangan Jumlah Kendaraan Bermotor di Indonesia," Badan Pusat Statistik, 2018. [Online]. Available: www. bps.go.id. [Accessed: 16-Jul-2020].

[2] I. N. Agus Adi, K. R. Dantes, and I. N. P. Nugraha, "Analisis Tegangan Statik Pada Rancangan Frame Mobil Listrik Ganesha Sakti (Gaski) Menggunakan Software Solidworks 2014," J. Pendidik. Tek. Mesin Undiksha, vol. 6, no. 2, p. 113, 2018, doi: 10.23887/jjtm.v6i2.13046.

[3] A. N. H. D. Alfino Adam Prayogo, Wandi Arnandi, "Perancangan dan pembuatan rangka pada go kart berbahan bakar gas lpg," Tek. Mesin, vol. I, p. 1, 2018.

[4] H. Sonawan, PERANCANGAN ELEMEN MESIN, Cetakan kedua. Bandung: ALFABETA, CV, 2014.

[5] M. Jurusan et al., "PERANCANGAN DAN SIMULASI FRAME MOBIL GOKART," vol. 3, no. 2, pp. 1-10, 2018.

[6] T. A. Henra Heny Sigarlaki, Stenly Tangkuman, “APLIKASI METODE ELEMEN HINGGA PADA PERANCANGAN POROS BELAKANG GOKAR LISTRIK Henra," Tek. Mesin, vol. 4, pp. 104-115, 2015.

[7] D. V, Machine Elements. Moscow: Foreign Languages Publishing House, 1988. 
METTEK Volume 7 No 1 (2021) pp 1 - 9

ojs.unud.ac.id/index.php/mettek

[8] P. H. H. Mustofa, "PERANCANGAN CHASSIS TYPE TUBULAR SPACE FRAME UNTUK KENDARAAN LISTRIK,” no. 23, pp. 9-17, 2017. 